\title{
Cancer stem cell and mesenchymal cell cooperative actions in metastasis progression and hormone resistance in prostate cancer: Potential role of androgen and gonadotropin-releasing hormone receptors (Review)
}

\author{
HÉCTOR R. CONTRERAS, FERNANDA LÓPEZ-MONCADA and ENRIQUE A. CASTELLÓN \\ Laboratory of Cellular and Molecular Oncology, Department of Basic and Clinical Oncology, \\ Faculty of Medicine, University of Chile, Santiago 8380453, Chile
}

Received July 18, 2019; Accepted January 9, 2020

DOI: 10.3892/ijo.2020.5008

\begin{abstract}
Prostate cancer (PCa) is the leading cause of male cancer-associated mortality worldwide. Mortality is associated with metastasis and hormone resistance. Cellular, genetic and molecular mechanisms underlying metastatic progression and hormone resistance are poorly understood. Studies have investigated the local effects of gonadotropin-releasing hormone $(\mathrm{GnRH})$ analogs (used for androgen deprivation treatments) and the presence of the GnRH receptor (GnRH-R) on PCa cells. Furthermore, cell subpopulations with stem-like properties, or cancer stem cells, have been isolated and characterized using a cell culture system derived from explants of human prostate tumors. In addition, the development of preclinical orthotopic models of human PCa in a nonobese diabetic/severe combined immunodeficiency mouse model of compromised immunity has enabled the establishment of a reproducible system of metastatic progression in vivo. There is increasing evidence that metastasis is a complex process involving the cooperative actions of different cancer cell subpopulations, in which cancer stem-like cells would be responsible for the final step of colonizing premetastatic niches. It has been hypothesized that PCa cells with stemness and mesenchymal signatures act cooperatively in metastatic progression and the inhibition of stemness genes, and that overexpression of androgen receptor (AR) and GnRH-R decreases the rate the metastasis and sensitizes tumors to hormone therapy. The aim of the present review is to analyze the evidence regarding this cooperative process and
\end{abstract}

Correspondence to: Dr Enrique A. Castellón, Laboratory of Cellular and Molecular Oncology, Department of Basic and Clinical Oncology, Faculty of Medicine, University of Chile, Independencia 1027, Santiago 8380453, Chile

E-mail: ecastell@med.uchile.cl

Key words: cancer stem cells, epithelial-mesenchymal transition, hormone resistance, androgen receptor, gonadotrophin-releasing hormone receptor, metastatic cooperation the possible influence of stem-like cell phenotypes, AR and GnRH-R in metastatic progression and hormone resistance. These aspects may represent an important contribution in the understanding of the mechanisms underlying metastasis and hormone resistance in $\mathrm{PCa}$, and potential routes to blocking these processes, enabling the development of novel therapies that would be particularly relevant for patients with metastatic and castration-resistant $\mathrm{PCa}$.

\section{Contents}

1. Introduction

2. Androgen deprivation and local effects of $\mathrm{GnRH}$ analogs in prostate cancer

3. Epithelial-mesenchymal transition and cancer stem cells in prostate cancer

4. Tumor cell phenotypic heterogeneity and metastatic processes

5. Different malignant cell types in a solid tumor may collaborate to produce distant metastasis

6. Orthotopic model for the study of human prostate cancer metastasis

7. Conclusions

\section{Introduction}

Prostate cancer $(\mathrm{PCa})$ is one of the major causes of male cancer-associated death worldwide (1). Over the last few decades, screening programs have increased early diagnosis and identified treatments with the potential to cure the disease (2-5). However, the high rates of recurrence and metastasis remain major challenges in treating PCa (6-12). During a long period of the disease, PCa can become sensitive to androgen treatment $(13,14)$. Testosterone controls cell proliferation, tumor growth and, potentially, dissemination (15-17), which is an advantage in treatments that involve androgen deprivation (AD), when curative surgery cannot be performed $(18,19)$. Pharmacological castration using gonadotropin-releasing hormone $(\mathrm{GnRH})$ analogs to 
block the hypothalamus-hypophysis-testicular axis provides the first-line treatment for disseminated PCa (20-22). However, during AD therapy, PCa cells frequently become androgen-resistant, resulting in a castration-resistant form of the disease with a poor prognosis (23-25). The genetic and molecular mechanisms underlying androgen resistance remain poorly understood (26-28). Research suggests that, in certain cases, the androgen receptor (AR) is involved in this resistance (29-31). On the other hand, recurrence and metastasis progression are complex processes that involve several mechanisms and genomic modifications of malignant cells $(32,33)$. It is well-known that epithelial-mesenchymal transition (EMT) is the main pathway via which malignant epithelial cells from carcinomas alter their gene expression profile to display a mesenchymal phenotype, acquiring, among other features, one of the hallmarks of cancer cells: Invasive behavior (34-38). However, increasing evidence indicates that tumors contain a phenotypically heterogeneous cell population, and that the cooperative action of these different types of malignant cells is potentially required to accomplish a successful metastatic process (39-42). In the past few years, a small subpopulation of malignant cells with stem-like properties has been identified in numerous types of cancer, including PCa $(43,44)$. These cells have been termed tumor-initiating cells (TICs) or cancer stem cells (CSCs), and are hypothesized to be responsible for recurrence and metastasis (45-48).

\section{Androgen deprivation and local effects of GnRH analogs in $\mathrm{PCa}$}

As aforementioned, GnRH analog therapy is the gold standard to treat disseminated PCa $(20,49)$. This treatment induces AD by blocking the hypothalamus-hypophysis-testicular axis, resulting in pharmacological castration. This type of therapy is very efficient at delaying tumor growth until PCa becomes castration-resistant (20). Gene amplification, mutations and other alterations in the AR gene have been identified (29,50-52). In addition, overexpression or constitutive activation of other proliferation signaling pathways that overcome androgen control have been reported $(53,54)$. In addition, alterations in androgen metabolism within the prostate gland have been associated with androgen sensitivity $(55,56)$. It is postulated that castration-resistant $\mathrm{PCa}$ arises from a combination of these different mechanisms. Our previous research, as well as other studies, have reported the presence of GnRH receptor (GnRH-R) in PCa cells (57-59). Furthermore, it has been observed that $\mathrm{GnRH}$ analogs induce proliferation arrest and apoptosis in $\mathrm{PCa}$ cells in a primary culture system $(57,58)$. GnRH-R expression increases from benign prostatic hyperplasia to medium histological grade (Gleason score 6-7), and subsequently decreases in samples from patients with higher Gleason scores (60). Local cellular effects of GnRH analogs may be of clinical relevance, as these effects remain despite cell androgen insensitivity $(58,60)$. Concentrations $>20 \mathrm{ng} / \mathrm{ml}$ are required to obtain significant in vitro apoptotic effects (61); however, the plasma concentrations in patients receiving AD treatment are below this level (62). This problem may be solved via intraprostatic administration of GnRH analogs. Unfortunately, patients who are castration-resistant often have a higher Gleason score and, as aforementioned, GnRH-R expression decreases with higher Gleason scores. There is evidence that GnRH-R in PCa, specifically in the gonadotropic cells, is retained primarily in the endoplasmic reticulum, where it can be moved to the plasma membrane using peptide-mimetic compounds called pharmacoperones (pharmacological chaperones) (60). Using this strategy, it is possible to increase GnRH-R expression in cultured PCa cells and sensitize them to the apoptotic effects of GnRH analogs (Fig. 1).

\section{EMT and CSCs in PCa}

EMT is a process in which an epithelial genetic program switches to a mesenchymal program; as a result, an epithelial cell loses its polarity, proliferation, and differentiation control and positioning, changing to a mesenchymal phenotype (63-65). This is a physiologically normal process occurring primarily during embryonic development (66). During carcinogenesis, similar genetic changes occur in carcinomas that transform a malignant epithelial cell into a highly proliferative and invasive mesenchymal-like cell $(65,67)$. Epithelial malignant cells progressively lose adhesion molecules, such as E-cadherin, syndecans and tight junction molecules, whereas gene-regulating factors, including Snail family transcriptional repressor SNAI1, SNAI2, zinc finger E-box-binding homeobox 1/2 and TWIST increase their expression, together with mesenchymal markers such as vimentin, $\mathrm{N}$-cadherin and metalloproteinases, resulting in an invasive cell phenotype $(35,38,68-70)$.

In PCa, syndecans are associated with Gleason score and EMT markers (71-73). It is hypothesized that this mesenchymal and invasive phenotype is responsible for the metastatic process $(68,74)$. However, there is no direct evidence that these mesenchymal cells (MCs) also have colonizing abilities. Conversely, increasing evidence suggests that a small population of malignant cells present in most types of tumor, CSCs, may be responsible for the final step in recurrence and metastasis (75-77). Our previous study identified and characterized a CSC population in PCa samples and determined their molecular stem signature (CD133 $\left./ \mathrm{CD}^{2} 4^{+} / \mathrm{ABCG} 2^{+} / \mathrm{CD} 24^{-}\right)$(78). In addition, proliferative, migratory, invasive and clonogenic abilities have been evaluated in this cell population (79). It is possible to separate this CSC population from mesenchymal-like cells by changing culture conditions, followed by magnetic-associated cells sorting (MACS) (78). In adherent conditions, most cells remain in a mesenchymal differentiate state, which has been determined from using specific markers and functional assays. However, in non-adherent conditions, most mesenchymal adherent cells die by anoikis (anchorage-dependent apoptosis), whereas a few cells survive, and rapidly form spheres that grow and remain for several weeks (78). Following MACS, separated sphere-forming cells represent an enriched CSC population (78). These CSCs exhibit a low proliferation rate, increased resistance to apoptosis and drug treatments, reduced invasive properties and a high clonogenic capacity compared with that in mesenchymal-adherent cells (79). In addition, these PCa CSCs have no expression of GnRH-R or AR, nor of numerous differentiation markers (79). Preliminary experiments within our laboratory using CSCs with stable expression of $A R$ and GnRH-R via lentiviral transduction suggest that these cells can become sensitive to androgens and GnRH analogs (unpublished data) (Fig. 2). 

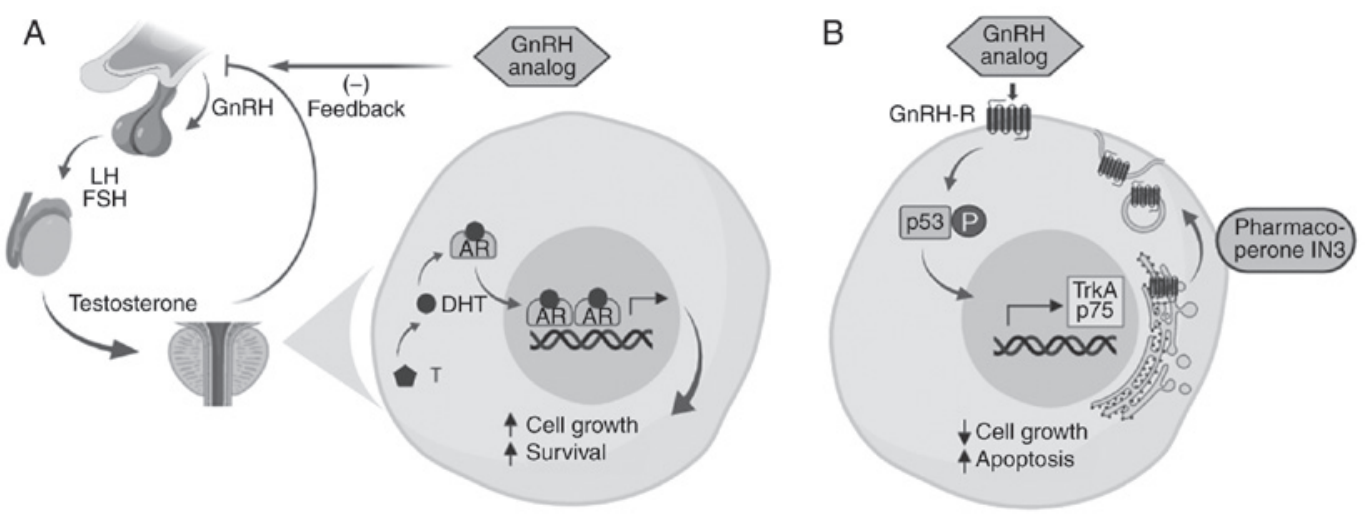

Figure 1. Comparison of systemic and local effects of GnRH analogs. (A) Systemic delivery of GnRH analogs blocks the hypothalamus-hypophysis-testicular axis, producing pharmacological castration that inhibits the AR-induced cell growth and survival of PCa cells. (B) Locally, in PCa cells, GnRH analogs activate GnRH-R, inducing phosphorylation of $\mathrm{p} 53$, and resulting in increased expression of TrkA and p75, which inhibits cell growth and stimulates the apoptosis of PCa cells. These effects can be potentiated with pharmacoperone IN3 by increasing GnRH-R availability in the cell membrane. AR, androgen receptor; DHT, dihydrotestosterone; FSH, follicle-stimulating hormone; GnRH, gonadotropin-releasing hormone; GnRH-R, GnRH receptor; LH, luteinizing hormone; PCa, prostate cancer; TrkA, tropomyosin receptor kinase A.

\section{Tumor cell phenotypic heterogeneity and metastatic processes}

It is becoming apparent that tumors present a significant degree of cell heterogeneity $(80,81)$. Tumor heterogeneity may be understood at the phenotypic and genetic level (82). Tumor cell phenotypic heterogeneity will specifically be discussed. Cellular and molecular mechanisms responsible for this heterogeneous cell population remain poorly understood. There remains controversy regarding the origin of CSCs, and several hypotheses have been suggested (76,83-85). However, regardless of the origin of CSCs, the relevant point, particularly for clinical application, is that such a population is present in the majority of cancers studied. The multifocal origin of cancer cells within the organ and the distinct differentiation fate during EMT process may explain, in part, this phenomenon $(75,86)$. As with the process of microevolution, cancer cells adapt to different microenvironments, first within the tumor niche and subsequently in potential metastatic niches $(87,88)$. Within the tumor, it is possible to find a hypoxic microenvironment, for instance in the center of a solid tumor, whereas in the periphery, where neoangiogenesis is occurring, a more oxygenated milieu is more prevalent $(89,90)$; cancer cells adapt differently to these distinct microenvironments. Therefore, it is possible that during EMT progression, certain cells express a stem gene program, forming a stable CSC population within a tumor (91-93).

Metastasis is an inefficient process; it is estimated that $<2 \%$ of total cancer cells entering the blood stream from a solid tumor will be able to colonize a premetastatic niche (94). Furthermore, $<0.02 \%$ will be able to survive in that niche and support sustained growth to give rise to clinically evident metastatic foci (94). Evidence suggests that this is not a stochastic process, indicating that not all malignant cells are able to sustain metastasis (94). Furthermore, very few cells have the ability to colonize, survive and grow in a tissue or organ different to the one from which it originated (95). The majority of researchers investigating CSCs have concluded that these metastatic cells express stemness genes and exhibit little invasive capacity (96). Previous results from our laboratory in CSCs from PCa are consistent with this hypothesis (78). Instead, PCa CSCs, as with other CSCs, have a low proliferation rate, high resistance to drugs and apoptosis (particularly anoikis), sphere-growing ability and a high clonogenic capacity (97-99). Determining how these CSCs, with little invasive activity, can leave the tumor and colonize premetastatic niches will be subsequently addressed.

Metastasis is a complex process. Premetastatic niches are developed in advance by several signals originating from the initiating tumor determining the tissue tropism of the future metastatic foci $(100,101)$. It is proposed that, once in the blood stream, CSCs are guided by homing signals from these premetastatic niches $(102,103)$. Once colonizing a metastatic site has begun, CSCs can be induced by niche milieu factors to survive and proliferate, or to become quiescent $(104,105)$. In the event of quiescence, future microenvironmental changes can subsequently induce cell proliferation and tumor growth, resulting in relapse, even if curative surgery was performed to remove the primary tumor (104). In human $\mathrm{PCa}$, bone is one of the main sites of distant metastasis (106). Stromal-cell-derived-factor 1 , acting through $\mathrm{C}-\mathrm{X}-\mathrm{C}$ chemokine receptor 4 on malignant cells, is hypothesized to promote cell survival in the niche (106). Secretion of several interleukins, tumor necrosis factor- $\alpha$ and other factors by cancer cells stimulates secretion of the receptor activator of NF- $\mathrm{KB}$ ligand (RANKL), which in turn stimulates osteoclast differentiation (107). Increased osteoclast activity releases bone matrix and growth factors that promote CSC survival and growth for metastatic progression (106-108). Exosomes secreted by CSCs and bulk cancer cell cultures derived from PCa contain various microRNAs (miRNAs/miRs). Comparing those miRNAs using next-generation sequencing followed by bioinformatics analysis, specific miRNAs, such as miR-100-5p, miR-21-5p and miR-139-5p were found to be overexpressed and, analyzed in an in vitro system, they increased the expression of metalloproteinases-2, -9 and -13 , and RANKL, as well as fibroblast migration, supporting the idea that the different $\mathrm{PCa}$ cells contribute cooperatively to prepare the premetastatic niche (100).

Considering that CSCs appear to be the only cells within a tumor with the ability to form metastasis, it is reasonable to propose that any increase in circulating CSCs will raise the risk 
A

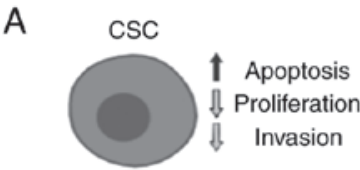

CD133+/CD44+/ABCG2+/CD24-

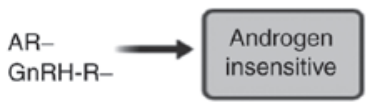

B

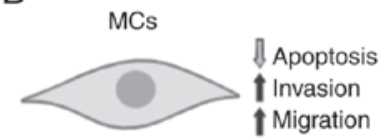

E-cadherin low/metalloproteases high

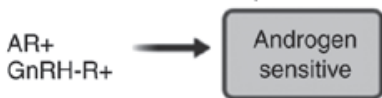

C

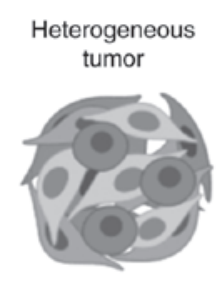

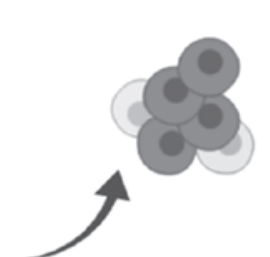

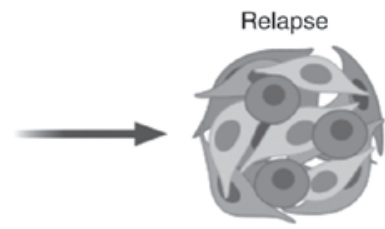

Accumulation of

$A D$ resistant $C S C$
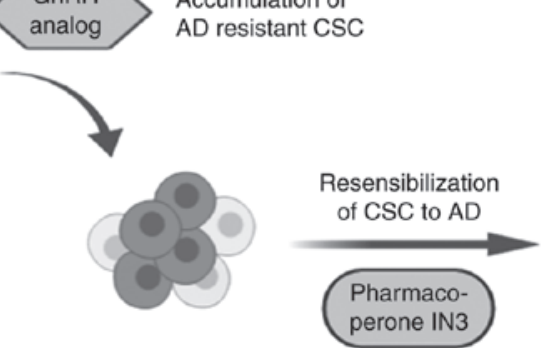

Long term remission

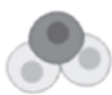

Figure 2. Resensibilization of CSCs to AD therapy could achieve long-term remission of metastatic CRPC. (A) CSCs are characterized by high resistance to apoptosis, low proliferation rates and low invasive capacities; as they do not express AR and GnRH-R, they are not responsive to AD therapies. (B) MCs have less resistance to apoptosis, and high invasive and migratory capacities; as they express AR and GnRH-R, they are responsive to AD therapies. (C) In a PCa tumor, characterized by heterogenous subpopulations, MCs represent the bulk of the tumor. CSCs and MCs cooperate to form metastases. MCs migrate and invade within the tumor stroma, allowing CSCs to escape to the circulation and grow in the metastatic niche, where they are able to grow and generate the full heterogeneity of the original tumor. After AD therapy with GnRH analogs, androgen-responsive MCs are in remission, but androgen-insensitive CSCs accumulate and the tumor returns. Resensibilization of CSCs to GnRH analogs using pharmacoperones or lentiviral transduction could lead to long-term remission of metastatic CRPC. AD, androgen deprivation; AR, androgen receptor; CRPC, castration-resistant PCa; CSC, cancer stem cell; MC, mesenchymal cell; GnRH, gonadotropin-releasing hormone; GnRH-R, GnRH receptor; PCa, prostate cancer.

of metastasis or recurrence $(88,109-111)$. Our previous study investigated the expression of stem signatures in PCa samples of different histological grades, using a tissue microarray and quantitative immunohistochemistry (78). It was observed that the number of cells expressing stem markers increases with Gleason grade, reaching maximal levels at medium Gleason, and decreasing thereafter in high-Gleason grade, lymph node and bone metastatic samples (78). Considering that malignant cells begin to enter the blood stream shortly after the tumor becomes locally invasive (low-to-medium histological grade), it is possible that a patient with a localized tumor with a medium Gleason score will contain the maximal number of CSCs potentially leaving the tumor and spreading throughout blood stream. At this stage, the indicated therapy is surgical removal of prostate gland (112). However, if CSCs already released from the tumor have seeded the metastatic niches, recurrence risk would be high. This is an important point to consider, particularly in patients with localized tumors of low Gleason grade where the therapeutic recommendation is active surveillance $(5,113)$. Therefore, identifying and quantifying CSCs in $\mathrm{PCa}$ biopsies may be a valuable prognostic factor for relapse.

\section{Different malignant cell types in a solid tumor may collaborate to produce distant metastasis}

Reanalyzing the problem of how CSCs with little invasive activity can leave the tumor and colonize premetastatic niches, it is reasonable to suggest that some type of collaboration with highly invasive mesenchymal-like cells occurs $(45,96)$. Previously, Celià-Terrassa et al (114) provided evidence regarding this potential cooperative action. Using commercial cell lines derived from PCa (PC3) and bladder cancer (TSU-Pr1), these were enriched with metastatic TICs, a cell population with a strong epithelial profile. In turn, they deprived TICs, a cell population with a mesenchymal profile. Overexpression of mesenchymal genes in the former cell population (epithelial phenotype) decreased its TIC ability, whereas knockdown of these genes in the latter cell population (mesenchymal phenotype) enhanced its TIC capacity (114). Using immunocompromised nonobese diabetic/severe combined immunodeficiency (NOD/SCID) mice, it was observed that, injected in combination, mesenchymal-like cells increased the metastatic potential of epithelial TIC-enriched cell populations, suggesting a cooperative action between both cell types (114). Subsequently, the same research group described that secreted protein acidic and rich in cysteine (SPARC) mediates the metastatic cooperation between CSC and non-CSC cell subpopulations (39).

Recently, it was reported that SPARC induced EMT, increasing the invasive capacities of PCa cells (115). Collectively, these findings support the hypothesis that within a tumor, MCs become the predominant population via EMT, increasing the invasive capacity of the tumor. However, it has been proposed that a small cell population that expresses a stem-like program (CSCs) remains in the tumor and can escape passively with the bulk of MCs. Once in the metastatic niche, it is hypothesized that CSCs proliferate and produce progenitor cells that may further differentiate to an epithelial-like phenotype. This may explain certain findings revealing that in metastatic PCa samples, an increase in epithelial markers and a decrease in mesenchymal markers is observed, which has been called mesenchymal-epithelial transition $(116,117)$. It is postulated that the metastatic foci will generate the full heterogeneity of the original tumor, in which epithelial-like cells will undergo EMT again, whilst a small number of CSCs are retained in the tumor. On the other hand, tumor cell plasticity influences the phenotypic heterogeneity of tumor cells, 
with the varied cell abilities enabling cooperation to promote cancer progression and metastasis. Differential cell distribution within the tumor, and spatial and temporal patterns during EMT-stemness processes may influence cell frequencies and the results of the proposed cell cooperation (118). This may contribute to why different patients with $\mathrm{PCa}$ at the same stage may have different outcomes.

Personalized medicine should take into consideration this evidence to develop novel and innovative therapeutic strategies. In this context, resensibilization of PCa cells (including CSCs) to $\mathrm{GnRH}$ analogs using pharmacoperones or lentiviral transduction may provide an effective treatment against metastatic castration-resistant PCa. It is necessary to validate this hypothesis using CSCs and MCs derived from the tumors of various patients. Metastasis is, by definition, a process that occurs in a living organism. Therefore, there are no in vitro models for investigating this complex pathological process. In previous years, several in vivo models have been developed (119-124). The majority of these use immunocompromised mice, and several mouse strains have been obtained, a number of them via transgenic manipulation (124-126). One of the most used models, at present, is the NOD/SCID mouse (127).

\section{Orthotopic model for the study of human PCa metastasis}

The NOD/SCID mouse has been widely used to investigate the metastasis of several types of human cancer (128). A critical issue is the type of injection used to introduce human cancer cells. Numerous researchers use subcutaneous, intravenous or intracardiac administration, with varying results $(114,129)$. Additionally, orthotopic models have been developed (injection in the same mouse organ or tissue from which human cells were derived). This model mimics the metastatic process more precisely (129). Reports of orthotopic models for human PCa have been published (130-132). A modification of the orthotopic model for PCa using a cell injection in one of the anterior lobes of the NOD/SCID mouse prostate has been developed by our laboratory $(133,134)$. This orthotopic injection results in consistent and reproducible metastatic progression. First, a fraction of tumor cells injected in the mouse prostate survives and generates a tumor derived from surviving injected cells (transduced with luciferase and red fluorescent protein genes). The fluorescence allows the tracking of metastatic progression in vivo using in vivo imaging equipment. In a chronological sequence, metastatic foci begin to appear in the liver, lungs and the kidneys. Injection of cells into the anterior lobe, instead of the ventral prostate, has the advantage that it is possible to surgically remove the prostate tumor to evaluate the progression of metastasis, with or without the primary prostate tumor. In this orthotopic model, the utility of prostatectomy during metastasis progression has been demonstrated (134), as has the effect of knocking down the stemness gene Sox 2 on metastasis (unpublished data). In current studies, progression towards a castration-resistant PCa mouse model using surgical castration as an AD strategy is being established.

\section{Conclusions}

In conclusion, it is proposed that there is cooperation between CSCs and MCs during metastatic progression. Further development of preclinical orthotopic models of PCa may provide additional evidence supporting this hypothesis. In addition, the role of stem genes, as well as AR, GnRH-R and differentiation genes, in metastasis progression and hormone resistance may have critical relevance. Further investigation of these aspects will contribute to the understanding of the cellular and molecular mechanisms of metastasis, recurrence and hormone resistance in $\mathrm{PCa}$, which remain major challenges for the treatment of this disease. It is predicted that evidence obtained using preclinical models, will be beneficial for clinical purposes in the near future, identifying novel prognostic factors and therapeutic targets.

\section{Acknowledgements}

The authors thank the professional contribution of Mrs Graciela Caroca (Laboratory of Cellular and Molecular Oncology, Department of Basic and Clinical Oncology, Faculty of Medicine, University of Chile) for assistance in the laboratory.

\section{Funding}

The present study was funded by Fondecyt (grant nos. 1140417 and 1151214), ENLACE-VID (grant nos. ENL-22/19 and ENL-23/19) and URedes URC (grant no. 007/17).

\section{Availability of data and materials}

All data generated or analyzed during this study are included in this published article.

\section{Authors' contributions}

HRC and FLM contributed to reviewing and discussing the literature, and selecting relevant studies. EAC analyzed the subject and wrote the review.

\section{Ethics approval and consent to participate}

Not applicable.

\section{Patient consent for publication}

Not applicable.

\section{Competing interests}

The authors declare that they have no competing interests.

\section{References}

1. Bray F, Ferlay J, Soerjomataram I, Siegel RL, Torre LA and Jemal A: Global cancer statistics 2018: GLOBOCAN estimates of incidence and mortality worldwide for 36 cancers in 185 countries. CA Cancer J Clin 68: 394-424, 2018.

2. Rodgers L, Peer CJ and Figg WD: Diagnosis, staging and risk stratification in prostate cancer: Utilizing diagnostic tools to avoid unnecessary therapies and side effects. Cancer Biol Ther 18: 470-472, 2017.

3. Shah RB and Zhou M: Recent advances in prostate cancer pathology: Gleason grading and beyond. Pathol Int 66: 260-272, 2016. 
4. Heijnsdijk EAM, Bangma CH, Borràs JM, de Carvalho TM, Castells X, Eklund M, Espinàs JA, Graefen M, Grönberg H, Lansdorp-Vogelaar I, et al: Summary statement on screening for prostate cancer in Europe. Int $\mathrm{J}$ Cancer 142: 741-746, 2018

5. Litwin MS and Tan HJ: The diagnosis and treatment of prostate cancer: A review. J Am Med Assoc 317: 2532-2542, 2017.

6. Ost P, Bossi A, Decaestecker K, De Meerleer G, Giannarini G, Karnes RJ, Roach M III and Briganti A: Metastasis-directed therapy of regional and distant recurrences after curative treatment of prostate cancer: A systematic review of the literature. Eur Urol 67: 852-863, 2015.

7. Fakhrejahani F, Madan RA and Dahut WL: Management options for biochemically recurrent prostate cancer. Curr Treat Options Oncol 18: 26, 2017.

8. Artibani W, Porcaro AB, De Marco V, Cerruto MA and Siracusano S: Management of biochemical recurrence after primary curative treatment for prostate cancer: A review. Urol Int 100: 251-262, 2018.

9. Sartor O and de Bono JS: Metastatic prostate cancer. N Engl J Med 378: 645-657, 2018.

10. Song C, Kang T, Yoo S, Jeong IG, Ro JY, Hong JH, Kim CS and Ahn H: Tumor volume, surgical margin, and the risk of biochemical recurrence in men with organ-confined prostate cancer. Urol Oncol 31: 168-174, 2013.

11. Suzman DL, Boikos SA and Carducci MA: Bone-targeting agents in prostate cancer. Cancer Metastasis Rev 33: 619-628, 2014.

12. Dong L, Zieren RC, Xue W, de Reijke TM and Pienta KJ: Metastatic prostate cancer remains incurable, why? Asian J Urol 6: 26-41, 2019

13. Pelekanou V and Castanas E: Androgen control in prostate cancer. J Cell Biochem 2234: 2224-2234, 2016.

14. Tan MH, Li J, Xu HE, Melcher K and Yong EL: Androgen receptor: Structure, role in prostate cancer and drug discovery. Acta Pharmacol Sin 36: 3-23, 2014.

15. Fujita K and Nonomura N: Role of androgen receptor in prostate cancer: A review. World J Mens Health 36: 288-295, 2018.

16. Rodriguez KM, Pastuszak AW and Khera M: The role of testosterone therapy in the setting of prostate cancer. Curr Urol Rep 19: 67, 2018.

17. Obinata D, Takayama K, Takahashi S and Inoue S: Crosstalk of the androgen receptor with transcriptional collaborators: Potential therapeutic targets for castration-resistant prostate cancer. Cancers (Basel) 9: pii: E22, 2017.

18. Grossmann M, Cheung AS and Zajac JD: Androgens and prostate cancer; pathogenesis and deprivation therapy. Best Pract Res Clin Endocrinol Metab 27: 603-616, 2013.

19. Hahn AW, Hale P, Rathi N and Agarwal N: Novel androgen axis systemic therapies for metastatic hormone-sensitive prostate cancer. Curr Opin Urol 27: 559-565, 2017.

20. Shore ND, Abrahamsson P, Anderson J, Crawford ED and Lange P: New considerations for ADT in advanced prostate cancer and the emerging role of $\mathrm{GnRH}$ antagonists. Prostate Cancer Prostatic Dis 16: 7-15, 2013.

21. Lama G, Papi M, Angelucci C, Maulucci G, Sica G and De Spirito M: Leuprorelin acetate long-lasting effects on GnRH receptors of prostate cancer cells: An atomic force microscopy study of agonist/receptor interaction. PLoS One 8: e52530, 2013.

22. Thomas BC and Neal DE: Androgen deprivation treatment in prostate cancer. BMJ 346: 1-5, 2013.

23. Katsogiannou M, Ziouziou H, Karaki S, Andrieu C, Henry de Villeneuve M and Rocchi P: The hallmarks of castration-resistant prostate cancers. Cancer Treat Rev 41: 588-597, 2015.

24. Yuan X, Cai C, Chen S, Chen S, Yu Z and Balk SP: Androgen receptor functions in castration-resistant prostate cancer and mechanisms of resistance to new agents targeting the androgen axis. Oncogene 33: 2815-2825, 2014

25. Fujimoto N: Role of the androgen-androgen receptor axis in the treatment resistance of advanced prostate cancer: From androgen-dependent to castration resistant and further. J UOEH 38: 129-138, 2016

26. Chandrasekar T, Yang JC, Gao AC and Evans CP: Mechanisms of resistance in castration-resistant prostate cancer (CRPC). Transl Androl Urol 4: 365-380, 2015.

27. Tilki D, Schaeffer EM and Evans CP: Understanding mechanisms of resistance in metastatic castration-resistant prostate cancer: The role of the androgen receptor. Eur Urol Focus 2: $499-505,2019$
28. Huang Y, Jiang X, Liang X and Jiang G: Molecular and cellula mechanisms of castration resistant prostate cancer. Oncol Lett 15: 6063-6076, 2018

29. Ho Y and Dehm SM: Androgen receptor rearrangement and splicing variants in resistance to endocrine therapies in prostate cancer. Endocrinology 158: 1533-1542, 2017.

30. Recouvreux MV, Wu JB, Gao AC, Zonis S, Chesnokova V, Bhowmick N, Chung LW and Melmed S: Androgen receptor regulation of local growth hormone in prostate cancer cells Endocrinology 158: 2255-2568, 2017.

31. Stelloo S, Nevedomskaya E, van der Poel HG, de Jong J, van Leenders GJ, Jenster G, Wessels LF, Bergman AM and Zwart W: Androgen receptor profiling predicts prostate cancer outcome. EMBO Mol Med 7: 1450-1464, 2015.

32. Höti N, Shah P, Hu Y, Yang S and Zhang H: Proteomics analyses of prostate cancer cells reveal cellular pathways associated with androgen resistance. Proteomics: 17, 2017 doi: 10.1002/pmic.201600228

33. Van Den Eeden SK, Lu R, Zhang N, Quesenberry CP Jr, Shan J, Han JS, Tsiatis AC, Leimpeter AD, Lawrence HJ, Febbo PG and Presti JC: A Biopsy-based 17-gene genomic prostate score as a predictor of metastases and prostate cancer death in surgically treated men with clinically localized disease. Eur Urol 73: 129-138, 2017.

34. Hanahan D and Weinberg RA: Hallmarks of cancer: The next generation. Cell 144: 646-674, 2011.

35. Nieto MA, Huang RY, Jackson RA and Thiery JP: EMT: 2016. Cell 166: 21-45, 2016

36. Hasegawa S, Nagano H, Konno M, Eguchi H, Tomokuni A, Tomimaru Y, Asaoka T, Wada H, Hama N, Kawamoto K, et al: A crucial epithelial to mesenchymal transition regulator, Sox4/Ezh2 axis is closely related to the clinical outcome in pancreatic cancer patients. Int J Oncol 48: 145-152, 2016.

37. Frisch SM, Schaller M and Cieply B: Mechanisms that link the oncogenic epithelial-mesenchymal transition to suppression of anoikis. J Cell Sci 126: 21-29, 2013.

38. Serrano-Gomez SJ, Maziveyi M and Alahari SK: Regulation of epithelial-mesenchymal transition through epigenetic and post-translational modifications. Mol Cancer 15: 18, 2016.

39. MateoF,Meca-Cortés O, Celià-Terrassa T,Fernández Y, AbasoloI, Sánchez-Cid L, Bermudo R, Sagasta A, Rodríguez-Carunchio L, Pons M, et al: SPARC mediates metastatic cooperation between CSC and non-CSC prostate cancer cell subpopulations. Mol Cancer 13: 237, 2014.

40. Lin KC, Torga G, Sun Y, Axelrod R, Pienta KJ, Sturm JC and Austin RH: The role of heterogeneous environment and docetaxel gradient in the emergence of polyploid, mesenchymal and resistant prostate cancer cells. Clin Exp Metastasis 36: 97-108, 2019.

41. Bakker B, Taudt A, Belderbos ME, Porubsky D, Spierings DC, de Jong TV, Halsema N, Kazemier HG, Hoekstra-Wakker K, Bradley A, et al: Single-cell sequencing reveals karyotype heterogeneity in murine and human malignancies. Genome Biol 17: 115, 2016.

42. Chapman MP, Risom T, Aswani AJ, Langer EM, Sears RC and Tomlin CJ: Modeling differentiation-state transitions linked to therapeutic escape in triple-negative breast cancer. PLoS Comput Biol 15: e1006840, 2019.

43. Eun K, Ham SW and Kim H: Cancer stem cell heterogeneity: Origin and new perspectives on CSC targeting. BMB Rep 50: 117-125, 2017.

44. Adamowicz J, Pakravan K, Bakhshinejad B, Drewa T and Babashah S: Prostate cancer stem cells: From theory to practice. Scand J Urol 51: 95-106, 2017.

45. Shahriari K, Shen F, Worrede-Mahdi A, Liu Q, Gong Y, Garcia FU and Fatatis A: Cooperation among heterogeneous prostate cancer cells in the bone metastatic niche. Oncogene 36: 2846-2856, 2017.

46. Chang L, Graham P, Hao J, Ni J, Deng J, Bucci J, Malouf D, Gillatt D and Li Y: Cancer stem cells and signaling pathways in radioresistance. Oncotarget 7: 11002-11017, 2016.

47. Geng SQ, Alexandrou AT and Li JJ: Breast cancer stem cells: Multiple capacities in tumor metastasis. Cancer Lett 349: 1-7, 2014.

48. Leão R, Domingos C, Figueiredo A, Hamilton R, Tabori U and Castelo-Branco P: Cancer stem cells in prostate cancer: Implications for targeted therapy. Urol Int 99: 125-136, 2017.

49. Rosario DJ, Davey P, Green J, Greene D, Turner B, Payne H and Kirby M: The role of gonadotrophin-releasing hormone antagonists in the treatment of patients with advanced hormone-dependent prostate cancer in the UK. World J Urol 34: $1601-1609,2016$ 
50. Poelaert F, Kumps C, Lumen N, Verschuere S, Libbrecht L Praet M, Rottey S, Claeys T, Ost P, Decaestecker K, et al: Androgen receptor gene copy number and protein expression in treatment-naïve prostate cancer. Urol Int 99: 222-228, 2017.

51. Prekovic S, van Royen ME, Voet AR, Geverts B, Houtman R, Melchers D, Zhang KY, Van den Broeck T, Smeets E, Spans L, et al: The effect of F877L and T878A mutations on androgen receptor response to enzalutamide. Mol Cancer Ther 15: 1702-1712, 2016.

52. Sutinen P, Malinen M, Heikkinen S and Palvimo JJ: SUMOylation modulates the transcriptional activity of androgen receptor in a target gene and pathway selective manner. Nucleic Acids Res 42 : 8310-8319, 2014

53. Rowlands MA, Holly JM, Hamdy F, Phillips J, Goodwin L, Marsden G, Gunnell D, Donovan J, Neal DE and Martin RM: Serum insulin-like growth factors and mortality in localised and advanced clinically detected prostate cancer. Cancer Causes Control 23: 347-354, 2012.

54. Lescarbeau RM, Seib FP, Prewitz M, Werner C and Kaplan DL: In vitro model of metastasis to bone marrow mediates prostate cancer castration resistant growth through paracrine and extracellular matrix factors. PLoS One 7: e40372, 2012

55. Penning TM and Tamae D: Current advances in intratumoral androgen metabolism in castration-resistant prostate cancer. Curr Opin Endocrinol Diabetes Obes 23: 264-270, 2016.

56. Price DK, Chau CH, Till C, Goodman PJ, Leach RJ, Johnson-Pais TL, Hsing AW, Hoque A, Parnes HL, Schenk JM, et al: Association of androgen metabolism gene polymorphisms with prostate cancer risk and androgen concentrations: Results from the prostate cancer prevention trial. Cancer 122: 2332-2340, 2016.

57. Clementi M, Sánchez C, Benitez DA, Contreras HR, Huidobro C, Cabezas J, Acevedo C and Castellón EA: Gonadotropin releasing hormone analogs induce apoptosis by extrinsic pathway involving p53 phosphorylation in primary cell cultures of human prostatic adenocarcinomas. Prostate 69: 1025-1033, 2009.

58. Sánchez C, Clementi M, Benitez D, Contreras H, Huidobro C and Castellón E: Effect of GnRH analogs on the expression of TrkA and p75 neurotrophin receptors in primary cell cultures from human prostate adenocarcinoma. Prostate 65: 195-202, 2005.

59. Angelucci C, Lama G, Iacopino F, Ferracuti S, Bono AV, Millar RP and Sica G: GnRH receptor expression in human prostate cancer cells is affected by hormones and growth factors. Endocrine 36: 87-97, 2009.

60. Sánchez CA, Mercado AJ, Contreras HR, Cabezas JC, Huidobro CC and Castellón EA: Pharmacoperone IN3 enhances the apoptotic effect of leuprolide in prostate cancer cells by increasing the gonadotropin-releasing hormone receptor in the cell membrane. Anticancer Drugs 23: 959-969, 2012.

61. Castellón E, Clementi M, Hitschfeld C, Sánchez C, Benítez D, Sáenz L, Contreras H and Huidobro C: Effect of leuprolide and cetrorelix on cell growth, apoptosis, and $\mathrm{GnRH}$ receptor expression in primary cell cultures from human prostate carcinoma. Cancer Invest 24: 261-268, 2006.

62. Saltzstein D, Shore ND, Moul JW, Chu F, Concepcion R de la Motte S, McLane JA, Atkinson S, Yang A and Crawford ED: Pharmacokinetic and pharmacodynamic comparison of subcutaneous versus intramuscular leuprolide acetate formulations in male subjects. Ther Adv Urol 10: 43-50, 2017.

63. Nieto MA and Cano A: The epithelial-mesenchymal transition under control: Global programs to regulate epithelial plasticity. Semin Cancer Biol 22: 361-368, 2012.

64. García de Herreros A and Baulida J: Cooperation, amplification, and feed-back in epithelial-mesenchymal transition. Biochim Biophys Acta 1825: 223-228, 2012.

65. Savagner P: The epithelial-mesenchymal transition (EMT) phenomenon. Ann Oncol 21 (Suppl 7): vii89-vii92, 2010.

66. Chen T, You Y, Jiang H and Wang ZZ: Epithelial-mesenchymal transition (EMT): A biological process in the development, stem cell differentiation, and tumorigenesis. J Cell Physiol 232: 3261-3272, 2017

67. Micalizzi DS, Farabaugh SM and Ford HL: Epithelial-mesenchymal transition in cancer: Parallels between normal development and tumor progression. J Mammary Gland Biol Neoplasia 15: 117-134, 2010.

68. De Craene B and Berx G: Regulatory networks defining EMT during cancer initiation and progression. Nat Rev Cancer 13: 97-110, 2013
69. Osorio LA, Farfán NM, Castellón EA and Contreras HR: SNAIL transcription factor increases the motility and invasive capacity of prostate cancer cells. Mol Med Rep 13: 778-786, 2016.

70. Orellana-Serradell O, Herrera D, Castellón EA and Contreras HR: The transcription factor ZEB1 promotes an aggressive phenotype in prostate cancer cell lines. Asian J Androl 20: 294-299, 2018.

71. Contreras HR, Ledezma RA, Vergara J, Cifuentes F, Barra C, Cabello P, Gallegos I, Morales B, Huidobro C and Castellón EA: The expression of syndecan-1 and -2 is associated with Gleason score and epithelial-mesenchymal transition markers, E-cadherin and beta-catenin, in prostate cancer. Urol Oncol 28: 534-540, 2010.

72. Poblete CE, Fulla J, Gallardo M, Muñoz V, Castellón EA Gallegos I and Contreras HR: Increased SNAIL expression and low syndecan levels are associated with high Gleason grade in prostate cancer. Int J Oncol 44: 647-654, 2014.

73. Farfán N, Ocarez N, Castellón EA, Mejía N, de Herreros AG and Contreras HR: The transcriptional factor ZEB1 represses Syndecan 1 expression in prostate cancer. Sci Rep 8: 11467, 2018

74. Montanari M, Rossetti S, Cavaliere C, D'Aniello C, Malzone MG, Vanacore D, Di Franco R, La Mantia E, Iovane G, Piscitelli R, et al: Epithelial-mesenchymal transition in prostate cancer: An overview. Oncotarget 8: 35376-35389, 2017.

75. Mitra A, Mishra L and Li S: EMT, CTCs and CSCs in tumor relapse and drug-resistance. Oncotarget 6: 10699-10710, 2015.

76. Peitzsch C, Tyutyunnykova A, Pantel K and Dubrovska A: Cancer stem cells: The root of tumor recurrence and metastases. Semin Cancer Biol 44: 10-24, 2017.

77. Ajani JA, Song S, Hochster HS and Steinberg IB: Cancer stem cells: The promise and the potential. Semin Oncol 42 (Suppl 1): S3-S17, 2015

78. Castellón EA, Valenzuela R, Lillo J, Castillo V, Contreras HR, Gallegos I, Mercado A and Huidobro C: Molecular signature of cancer stem cells isolated from prostate carcinoma and expression of stem markers in different Gleason grades and metastasis. Biol Res 45: 297-305, 2012.

79. Castillo V, Valenzuela R, Huidobro C, Contreras HR and Castellon EA: Functional characteristics of cancer stem cells and their role in drug resistance of prostate cancer. Int J Oncol 45: 985-994, 2014.

80. McGranahan N and Swanton C: Clonal heterogeneity and tumor evolution: Past, present, and the future. Cell 168: 613-628, 2017.

81. Bosman FT: Tumor heterogeneity: Will it change what pathologists do. Pathobiology 85: 18-22, 2018

82. Jolly MK and Celià-Terrassa T: Dynamics of phenotypic heterogeneity during EMT and stemness in cancer progression. J Clin Med 8: pii: E1542, 2019.

83. Bu Y and Cao D: The origin of cancer stem cells. Front Biosci (Schol Ed) 4: 819-830, 2012.

84. Parsons BL: Multiclonal tumor origin: Evidence and implications. Mutat Res 777: 1-18, 2018.

85. Vicente-Dueñas C, Hauer J, Cobaleda C, Borkhardt A and Sánchez-García I: Epigenetic priming in cancer initiation. Trends Cancer 4: 408-417, 2018.

86. Ye X and Weinberg RA: Epithelial-mesenchymal plasticity: A central regulator of cancer progression. Trends Cell Biol 25: 675-686, 2015

87. Graham TA and Sottoriva A: Measuring cancer evolution from the genome. J Pathol 241: 183-191, 2017.

88. Francart M, Lambert J, Vanwynsberghe AM, Thompson EW, Bourcy M, Polette M and Gilles C: Epithelial-mesenchymal plasticity and circulating tumor cells: Travel companions to metastases. Dev Dyn 247: 432-450, 2018.

89. Carnero A and Lleonart M: The hypoxic microenvironment: A determinant of cancer stem cell evolution. Bioessays 38 (Suppl 1): S65-S74, 2016

90. Yeo CD, Kang N, Choi SY, Kim BN, Park CK, Kim JW, Kim YK and Kim SJ: The role of hypoxia on the acquisition of epithelial-mesenchymal transition and cancer stemness: A possible link to epigenetic regulation. Korean J Intern Med 32: 589-599, 2017.

91. Rhim AD: Epithelial to mesenchymal transition and the generation of stem-like cells in pancreatic cancer. Pancreatology 13 114-117, 2013.

92. Lan L, Luo Y, Cui D, Shi BY, Deng W, Huo LL, Chen HL, Zhang GY and Deng LL: Epithelial-mesenchymal transition triggers cancer stem cell generation in human thyroid cancer cells. Int J Oncol 43: 113-120, 2013. 
93. Li N, Babaei-Jadidi R, Lorenzi F, Spencer-Dene B, Clarke P, Domingo E, Tulchinsky E, Vries RGJ, Kerr D, Pan Y, et al: An FBXW7-ZEB2 axis links EMT and tumour microenvironment to promote colorectal cancer stem cells and chemoresistance. Oncogenesis 8: 13, 2019.

94. Croker AK and Allan AL: Cancer stem cells: Implications for the progression and treatment of metastatic disease. J Cell Mol Med 12: 374-390, 2008.

95. Massagué $\mathrm{J}$ and Obenauf AC: Metastatic colonization by circulating tumour cells. Nature 529: 298-306, 2016.

96. Hayashida T, Jinno H, Kitagawa Y and Kitajima M: Cooperation of cancer stem cell properties and epithelial-mesenchymal transition in the establishment of breast cancer metastasis. J Oncol 2011: 591427, 2011.

97. Hsu CL, Chung FH, Chen CH, Hsu TT, Liu SM, Chung DS, Hsu YF, Chen CL, Ma N and Lee HC: Genotypes of cancer stem cells characterized by epithelial-to-mesenchymal transition and proliferation related functions. Sci Rep 6: 32523, 2016.

98. Yun EJ, Lo UG and Hsieh JT: The evolving landscape of prostate cancer stem cell: Therapeutic implications and future challenges. Asian J Urol 3: 203-210, 2016.

99. Lin CJ, Lo UG and Hsieh JT: The regulatory pathways leading to stem-like cells underlie prostate cancer progression. Asian J Androl 21: 233-240, 2019.

100. Sánchez CA, Andahur EI, Valenzuela R, Castellón EA, Fullá JA, Ramos CG and Triviño JC: Exosomes from bulk and stem cells from human prostate cancer have a differential microRNA content that contributes cooperatively over local and pre-metastatic niche. Oncotarget 7: 3993-4008, 2016.

101. Hoshino A, Costa-Silva B, Shen TL, Rodrigues G, Hashimoto A, Tesic Mark M, Molina H, Kohsaka S, Di Giannatale A, Ceder S, et al: Tumour exosome integrins determine organotropic metastasis. Nature 527: 329-335, 2015.

102. Langley RR and Fidler IJ: The seed and soil hypothesis revisited-The role of tumor-stroma interactions in metastasis to different organs. Int J Cancer 128: 2527-2535, 2011.

103. Miftakhova R, Hedblom A, Semenas J, Robinson B, Simoulis A, Malm J, Rizvanov A, Heery DM, Mongan NP, Maitland NJ, et al: Cyclin A1 and P450 aromatase promote metastatic homing and growth of stem-like prostate cancer cells in the bone marrow. Cancer Res 76: 2453-2464, 2016.

104. Shiozawa Y, Berry JE, Eber MR, Jung Y, Yumoto K, Cackowski FC, Yoon HJ, Parsana P, Mehra R, Wang J, et al: The marrow niche controls the cancer stem cell phenotype of disseminated prostate cancer. Oncotarget 7: 41217-41232,2016.

105. Sharma S, Xing F, Liu Y, Wu K, Said N, Pochampally R, Shiozawa Y, Lin HK, Balaji KC and Watabe K: Secreted protein acidic and rich in cysteine (SPARC) mediates metastatic dormancy of prostate cancer in the bone. J Biol Chem 291: 19351-19363, 2016.

106. Jin J, Dayyani F and Gallick G: Steps in prostate cancer progression that lead to bone metastasis. Int J Cancer 128: 2545-2561, 2011.

107. Peyruchaud O, Leblanc R and David M: Pleiotropic activity of lysophosphatidic acid in bone metastasis. Biochim Biophys Acta 1831: 99-104, 2013

108. Roodman GD: Genes associate with abnormal bone cell activity in bone metastasis. Cancer Metastasis Rev 31: 569-578, 2012.

109. Zhang T and Armstrong AJ: Clinical utility of circulating tumor cells in advanced prostate cancer. Curr Oncol Rep 18: 3, 2016.

110. Barriere G, Fici P, Gallerani G, Fabbri F, Zoli W and Rigaud M: Circulating tumor cells and epithelial, mesenchymal and stemness markers: Characterization of cell subpopulations. Ann Transl Med 2: 109, 2014

111. Vogelzang NJ, Fizazi K, Burke JM, De Wit R, Bellmunt J, Hutson TE, Crane E, Berry WR, Doner K, Hainsworth JD, et al Circulating tumor cells in a phase 3 study of docetaxel and prednisone with or without lenalidomide in metastatic Castration-resistant prostate cancer. Eur Urol 71: 168-171, 2017.

112. Srivatsa N, Nagaraja H, Shweta S and Raghunath S: Radical prostatectomy for locally advanced prostate cancers-review of literature. Indian J Surg Oncol 8: 175-180, 2017.

113. Wilt T, Brawe M, Jones K, Barry MJ, Aronson WJ, Fox S, Gingrich JR, Wei JT, Gilhooly P, Grob BM, et al: Radical prostatectomy versus observation for localized prostate cancer. N Engl J Med 367: 203-213, 2012.

114. Celià-Terrassa T, Meca-Cortés Ó, Mateo F, Martínez de Paz A, Rubio N, Arnal-Estapé A, Ell BJ, Bermudo R, Díaz A, Guerra-Rebollo M, et al: Epithelial-mesenchymal transition can suppress major attributes of human epithelial tumor-initiating cells. J Clin Invest 122: 1846-1868, 2012.
115. López-Moncada F, Torres MJ, Castellón EA and Contreras HR: Secreted protein acidic and rich in cysteine (SPARC) induces epithelial-mesenchymal transition, enhancing migration and invasion, and is associated with high Gleason score in prostate cancer. Asian J Androl 21: 557-564, 2019.

116. Gunasinghe NP, Wells A, Thompson EW and Hugo HJ: Mesenchymal-epithelial transition (MET) as a mechanism for metastatic colonisation in breast cancer. Cancer Metastasis Rev 31: 469-478, 2012

117. Bullock MD, Sayan AE, Packham GK and Mirnezami AH MicroRNAs: Critical regulators of epithelial to mesenchymal (EMT) and mesenchymal to epithelial transition (MET) in cancer progression. Biol Cell 104: 3-12, 2012.

118. Bocci F, Gearhart-Serna L, Boareto M, Ribeiro M, Ben-Jacob E, Devi GR, Levine H, Onuchic JN and Jolly MK: Toward understanding cancer stem cell heterogeneity in the tumor microenvironment. Proc Natl Acad Sci USA 116: 148-157, 2019.

119. Harris JE, Shin J, Lee B, Pelosky K, Hooker CM, Harbom K, Hulbert A, Zahnow C, Yang SC, Baylin S, et al: A murine xenograft model of spontaneous metastases of human lung adenocarcinoma. J Surg Res 171: e75-e79, 2011.

120. Rea D, Del Vecchio V, Palma G, Barbieri A, Falco M, Luciano A, De Biase D, Perdonà S, Facchini G and Arra C: Mouse models in prostate cancer translational research: From Xenograft to PDX. Biomed Res Int 2016: 11, 2016.

121. Daphu I, Sundstrøm T, Horn S, Huszthy PC, Niclou SP, Sakariassen PØ, Immervoll $\mathrm{H}$, Miletic H, Bjerkvig R and Thorsen F: In vivo animal models for studying brain metastasis: Value and limitations. Clin Exp Metastasis 30: 695-610, 2013.

122. Romano G, Chagani S and Kwong LN: The path to metastatic mouse models of colorectal cancer. Oncogene 37: 2481-2489, 2018

123. Kahn J, Tofilon PJ and Camphausen K: Preclinical models in radiation oncology. Radiat Oncol 7: 223, 2012.

124. Loi M, Di Paolo D, Becherini P, Zorzoli A, Perri P, Carosio R, Cilli M, Ribatti D, Brignole C, Pagnan G, et al: The use of orthotopic models to validate antivascular therapies for cancer. Int J Dev Biol 55: 547-555, 2011

125. Grabowska MM, Degraff DJ, Yu X, Jin RJ, Chen Z, Borowsky AD and Matusik RJ: Mouse models of prostate cancer: Picking the best model for the question. Cancer Metastasis Rev 33: 377-397, 2014.

126. Usary J, Zhao W, Darr D, Roberts PJ, Liu M, Balletta L, Karginova O, Jordan J, Combest A, Bridges A, et al: Predicting drug responsiveness in human cancers using genetically engineered mice. Clin Cancer Res 19: 4889-4899, 2013.

127. Bastide C, Bagnis C, Mannoni P, Hassoun J and Bladou F: A Nod Scid mouse model to study human prostate cancer. Prostate Cancer Prostatic Dis 5: 311-315, 2002.

128. Hidalgo M, Amant F, Biankin AV, Budinská E, Byrne AT, Caldas C, Clarke RB, de Jong S, Jonkers J, Mælandsmo GM, et al: Patient derived xenograft models: An emerging platform for translational cancer research. Cancer Discov 4: 998-1013, 2014.

129. Dai J, Hensel J, Wang N, Kruithof-de Julio M and Shiozawa Y: Mouse models for studying prostate cancer bone metastasis. Bonekey Rep 5: 777, 2016

130. Tumati V, Mathur S, Song K, Hsieh JT, Zhao D, Takahashi M, Dobin T, Gandee L, Solberg TD, Habib AA and Saha D: Development of a locally advanced orthotopic prostate tumor model in rats for assessment of combined modality therapy. Int J Oncol 42: 1613-1619, 2013.

131. Lee ST, Wong PF, He H, Hooper JD and Mustafa MR: Alpha-tomatine attenuation of in vivo growth of subcutaneous and orthotopic xenograft tumors of human prostate carcinoma PC-3 cells is accompanied by inactivation of nuclear factor-Kappa B signaling. PLoS One 8: e57708, 2013.

132. Wang Y, Xue H, Cutz JC, Bayani J, Mawji NR, Chen WG, Goetz LJ, Hayward SW, Sadar MD, Gilks CB, et al: An orthotopic metastatic prostate cancer model in SCID mice via grafting of a transplantable human prostate tumor line. Lab Invest 85: 1392-1404, 2005.

133. Cifuentes FF, Valenzuela RH, Contreras HR and Castellón EA Development of an orthotopic model of human metastatic prostate cancer in the NOD-SCID $\gamma$ mouse (Mus musculus) anterior prostate. Oncol Lett 10: 2142-2148, 2015.

134. Cifuentes FF, Valenzuela RH, Contreras HR and Castellón EA: Surgical cytoreduction of the primary tumor reduces metastatic progression in a mouse model of prostate cancer. Oncol Rep 34: 2837-2844, 2015. 